\title{
H-Reflex Modulation During Walking In Spastic Paretic Subjects
}

\author{
J.F. Yang, J. Fung, M. Edamura, R. Blunt, R.B. Stein and H. Barbeau
}

\begin{abstract}
Hoffmann $(\mathrm{H})$ reflexes were elicited from the soleus muscle during treadmill walking in 21 spastic paretic patients. The soleus and tibialis anterior muscles were reciprocally activated during walking in most patients, much like that observed in healthy individuals. The pattern of H-reflex modulation varied considerably between patients, from being relatively normal in some patients to a complete absence of modulation in others. The most common pattern observed was a lack of $\mathrm{H}$-reflex modulation through the stance phase and slight depression of the reflex in the swing phase, considerably less modulation than that of normal subjects under comparable walking conditions. The high reflex amplitudes during periods of the step cycle such as early stance seems to be related to the stretch-induced large electromyogram bursts in the soleus in some subjects. The abnormally active reflexes appear to contribute to the clonus encountered during walking in these patients. In three patients who were able to walk for extended periods, the effect of stimulus intensity was examined. Two of these patients showed a greater degree of reflex modulation at lower stimulus intensities, suggesting that the lack of modulation observed at higher stimulus intensities is a result of saturation of the reflex loop. In six other patients, however, no reflex modulation could be demonstrated even at very low stimulus intensities.
\end{abstract}

RÉSUMÉ: Modulation du refléxe-H pendant la marche chez des patients parétiques spastiques Le réflexe de Hoffmann $(\mathrm{H})$ dans le muscle soléaire a été étudié durant la marche sur tapis roulant chez un groupe de 21 patients parésiques spastiques. La majorité des patients, montre une activité électromyographique (EMG) réciproque entre les muscles tibial antérieur et soléaire, similaire à celle observée chez les sujets normaux. Le patron de modulation du réflexe-H varie grandement chez ces patients, passant d'un patron presque normal à une absence complète de modulation. Le patron le plus fréquemment observé est une absence de modulation durant la phase d'appui avec une inhibition partielle durant la phase d'oscillation. Chez certains patients, une augmentation d'amplitude du réflexe-H au début de la phase d'appui pourrait être relié, en partie, à un réflexe d'étirement du muscle soléaire. Cette activité réflexe anormale pourrait contribuer à la présence de clonus durant la marche. De plus, chez trois patients qui peuvent marcher pour une plus longue période de temps. l'effet de l'intensité de stimulation a aussi été étudié. A des intensités de stimulation plus basses, une plus grande modulation de l'amplitude du réflexe-H a été observée chez deux de ces patients. Ces résultats suggèrent qu'une saturation de l'arc réflexe pourrait expliquer le manque de modulation du réflexe-H à de plus hautes intensités de stimulation. Aucune modulation réflexe n'a été observée chez six autres patients parésiques spastiques, même à de très basses intensités de stimulation.

Can. J. Neurol. Sci. 1991; 18: 443-452

Segmental reflexes are highly modulated during locomotion as a function of the phase in the step cycle. ${ }^{i-4}$ Moreover, the amplitude of the Hoffmann $(\mathrm{H})$ reflex can vary as a function of the locomotor task. 5 These reflex modulations appear to be functionally important for the control of locomotion. 5,6

Injury to the central nervous system (CNS), which interrupts descending input to the spinal cord, often results in altered excitability of segmental reflexes (e.g., reviewed in Ashby and McCrea ${ }^{7}$ ). After the initial period of spinal shock, reflexes associated with the muscle spindle (i.e., the tendon jerk and $\mathrm{H}$ reflex) gradually become exaggerated. $8-11$ The hyperactive reflexes observed at rest may persist during movement.
Debate continues on whether hyperactive stretch reflexes contribute to problems in motor control. ${ }^{12,13}$ Reduction of these exaggerated responses is possible by pharmacological means in some patients. ${ }^{14}$ Yet, reduced stretch responses have reportedly improved movement in some cases 15,16 or not affected the quality of movement in others. ${ }^{12}$ To interpret these results, we must understand: 1) how the reflex is normally modulated in movement, 2) how the reflex modulation pattern is changed in patients, and 3) whether the treatment interventions are able to restore a more normal modulation of the reflex and, hopefully, a more normal movement pattern. These three aspects have not been addressed in the previous studies.

From the Division of Neuroscience (J.F.Y., M.E., R.B.S.); Departments of Physical Therapy (J.F.Y.) and Physiology (M.E., R.B.S.), University of Alberta, Edmonton, and School of Physical and Occupational Therapy (J.F., R.B., H.B.), McGill University, Montreal

Received January 3, 1991. Accepted in final form June 14, 1991

Reprint requests to: J.F. Yang, Division of Neuroscience, 513 Heritage Medical Research Ctr., University of Alberta, Edmonton, Alberta, Canada T6G 2S2 
The soleus (SOL) H-reflex is deeply modulated during walking in normal subjects. ${ }^{3-5}$ The reflex is largely monosynaptic and related to the stretch reflex, which is clearly augmented in many patients after injury to the CNS. ${ }^{8-11}$ Hence, the H-reflex is a logical choice for examining reflex modulation in patients. If the reflex amplitude is abnormally high in the patients, then treatment strategies might be directed towards lowering the reflex response. Alternatively, if the mechanisms for generating the phasic modulation during walking is impaired, methods would have to be developed which replace this modulation artificially.

H-reflexes were elicited during walking in a group of spastic paretic subjects. The results indicated that the degree of reflex modulation during walking was reduced in these patients. The reason for this reduction could be an abnormally active reflex loop, or the absence of phasic modulation. Preliminary results have been reported in abstract form. 17,18

\section{METHODS}

The experiments were performed on 21 patients in two centres, Montreal and Edmonton (10 and 11 patients respectively). Fourteen patients suffered from incomplete spinal cord injury, three from head injury, one from both spinal cord and head injury and three suffered from spastic paresis of non-familial origin. Relevant demographic information on the patients is shown in Table 1. All patients were clinically stabilized at the time of testing, and all showed signs of hyperactive stretch responses in the triceps surae muscle group. Some were on medications such as baclofen and cyproheptadine to reduce these responses. All patients gave informed consent.

The ambulatory ability of these patients varied. Thirteen were able to walk on the treadmill with aids (i.e., crutches or handrail support) at speeds ranging from 0.1 to $0.8 \mathrm{~m} / \mathrm{s}$. Eight patients from Edmonton could not walk at the lowest treadmill speed of $0.6 \mathrm{~m} / \mathrm{s}$ at that centre, but were able to generate walking movements with a single leg on the treadmill belt, while the other leg remained stationary off the belt. For reasons of safety, some patients were fitted with a body harness while on the treadmill. The harness did not support their body weight, but rather was used to prevent them from falling.

Surface electromyograms (EMGs) were recorded from the SOL and tibialis anterior (TA) muscles with bipolar surface electrodes (approximately $8 \mathrm{~mm}$ in diameter). The electrodes were placed $2 \mathrm{~cm}$ apart near the motor point of the TA, and over the SOL muscle just distal to the insertion of the gastrocnemius muscle into the Achilles tendon. The EMG's were bandpass fil-

Table 1: Demographic Information on the Patients.

\begin{tabular}{|c|c|c|c|c|c|c|c|c|c|}
\hline Code & Age & Sex & Diagnosis & $\begin{array}{l}\text { Ankle } \\
\text { Clonus }\end{array}$ & $\begin{array}{l}\text { Years } \\
\text { Since } \\
\text { Injury }\end{array}$ & $\begin{array}{l}\text { MI } \\
(\%)\end{array}$ & $\underset{(\%)}{\operatorname{MI}(\mathbf{s})}$ & $\begin{array}{c}\text { Foot } \\
\text { Contact }\end{array}$ & Ambulatory Status \\
\hline $\mathrm{CH} 3$ & 32 & $\mathbf{M}$ & $\mathrm{C}_{5-6} \mathrm{SCI}$ & $S$ & 1.3 & 94 & 30 & $\mathrm{TC}$ & Canadian crutches, FES(L) \\
\hline${ }^{*} \mathrm{RM}$ & 35 & $\mathbf{M}$ & $\mathrm{C}_{6} \mathrm{SCI}$ & $\mathrm{U}$ & 19.5 & 93 & 82 & $\mathrm{TC}$ & Canadian crutches \\
\hline $\mathrm{RB}$ & 23 & $\mathbf{M}$ & HI & $\mathrm{U}$ & 0.4 & 92 & 60 & TC & Independent \\
\hline $\mathrm{CF}$ & 26 & $\mathbf{M}$ & $\mathrm{C}_{6-7} \mathrm{SCI}$ & $S$ & 6.5 & 89 & 40 & $\mathrm{TC}$ & Canadian crutches, SLB(R) \\
\hline $\mathrm{BP} 2$ & 32 & $\mathbf{M}$ & $\mathrm{C}_{5-6} \mathrm{SCI}$ & $S$ & 9.3 & 88 & 42 & $\mathrm{HC}$ & Walker, FES(B) \\
\hline RG & 43 & $\mathbf{M}$ & $\mathrm{C}_{3-4} \mathrm{SCI}$ & $U$ & 0.2 & 83 & 51 & $\mathrm{HC}$ & Walker \\
\hline BK & 21 & $\mathbf{M}$ & $\mathrm{T}_{5-6} \mathrm{SCI}$ & $S$ & 5.0 & 72 & 23 & $\mathrm{TC}$ & Walker\#, FES(B) or SLB(B) \\
\hline${ }^{*} \mathrm{LR}$ & 24 & F & $\mathrm{T}_{10} \mathrm{SCI}$ & $\mathrm{U}$ & 3.5 & 65 & 86 & $\mathrm{HC}$ & 1 cane, $\operatorname{SLB}(\mathrm{R})$ \\
\hline${ }^{*} \mathrm{BP} 1$ & 34 & $\mathbf{M}$ & SP & $\mathbf{U}$ & 5.0 & 55 & 2 & $\mathrm{HC}$ & Independent, SLB(B) \\
\hline JT & 43 & $\mathbf{M}$ & $\mathrm{C}_{6-7} \mathrm{SCI}$ & $\mathrm{U}$ & 0.8 & 47 & 34 & $\mathrm{HC}$ & Walker\#, SLB(R) \\
\hline AN & 22 & $\mathbf{M}$ & $\mathrm{SP}$ & $\mathbf{U}$ & 10.0 & 32 & 32 & $\mathrm{HC}$ & Independent but unstable \\
\hline${ }^{*} \mathrm{CHI}$ & 55 & $\mathbf{M}$ & $\mathrm{T}_{8} \mathrm{SCI}$ & $S$ & 2.0 & 30 & 24 & $\mathrm{TC}$ & Walker\#, SLB(R) \\
\hline *SH & 29 & $\mathbf{M}$ & $\mathrm{C}_{7-8} \mathrm{SCI}$ & $S$ & 4.5 & 26 & 26 & $\mathrm{TC}$ & Walker\#, SLB(B) \\
\hline *GB 1 & 30 & $\mathbf{M}$ & $\mathrm{C}_{5-6} \mathrm{SCI}$ & $S$ & 4.3 & 18 & 8 & $\mathrm{HC}$ & Canadian crutches \\
\hline
\end{tabular}

$\mathrm{SCI}$ - spinal cord injury

$\mathrm{HI}$ - head injury

SP - spastic paresis of non-familial origin

$\mathrm{U}$ - unsustained clonus

$S$ - sustained clonus

MI - H-reflex modulation index over the step cycle
MI(s) - H-reflex modulation index during early stance phase

\#- non-functional, 5-10 steps at a time with maximal effort

SLB - short leg brace on the right (R), left (L) or bilaterally (B)

FES - functional electrical stimulation

$\mathrm{HC}$ - heel contact

TC - toe contact

The data are presented in descending order of the modulation index (MI) recorded over the step cycle. Those patients whose data are illustrated in the figures are indicated with *. The foot contact patterns of heel contact (HC) and toe contact (TC) were determined from the foot switch signals obtained during treadmill walking. 
tered at $10 \mathrm{~Hz}$ to $1 \mathrm{kHz}$ in Montreal, and $10 \mathrm{~Hz}$ to $10 \mathrm{kHz}$ in Edmonton. The difference in the bandpass range simply reflected the different characteristics of the preamplifiers at the two centres. This raw signal from the SOL muscle was used to study H-reflexes. The signals from both muscles were also full-wave rectified and low-pass filtered at $30 \mathrm{~Hz}$ to study the EMG patterns during undisturbed walking. Contact switches attached to the sole of the ipsilateral shoe indicated the time of foot-floor contact, and triggered averaging of the EMG during undisturbed walking (between 10 to 30 strides).

H-reflexes were elicited from the SOL muscle in the conventional way by stimulating the tibial nerve. 19 The cathode was a disk electrode (similar to the recording electrodes), placed in the popliteal fossa at a location which was optimal for eliciting the $\mathrm{H}$-reflex from the SOL. The anode was placed above the patella on the anterior aspect of the thigh. Single, monophasic pulses 1 $\mathrm{ms}$ in duration were used to elicit the response. The stimulus intensity was chosen to be as low as possible with the M-wave still visible.

Reflexes were elicited at random intervals from 1 to $8 \mathrm{~s}$ apart while the subjects were walking. These intervals are longer than those typically used with normal subjects, because the stimuli sometimes elicited clonus in these patients. The longer interpulse interval minimized the influence of these late responses.

The step cycle was divided into equal time segments, and responses to stimuli which arrived within the same segment of the step cycle were averaged together (approximately 5 to 10 per segment), at a sampling rate of between 3 to $4 \mathrm{kHz}$, as previously reported. ${ }^{3}$ Software restricted the division of the step cycle into either 8 or 16 segments, 8 if both means and standard deviations were calculated, and 16 if only means were calculated.

The effective stimulus strength varied through the step cycle because of large movements at the knee. The experiment was repeated at different stimulus intensities, so that $\mathrm{H}$-reflexes elicited at the same effective stimulus strength (as indicated by the $\mathbf{M}$-wave amplitude) could be compared for all parts of the step cycle. Generally, four repeat trials, each requiring approximately 3 to 10 minutes of continuous walking, were needed to obtain an adequate match of the effective stimulus strength. Patients were given ample rest periods between trials to minimize the effect of fatigue.

A number of confounding factors were present. First, the mode and speed of locomotion had to be adapted to the ability of each patient. In order to compare the patient group with nor-

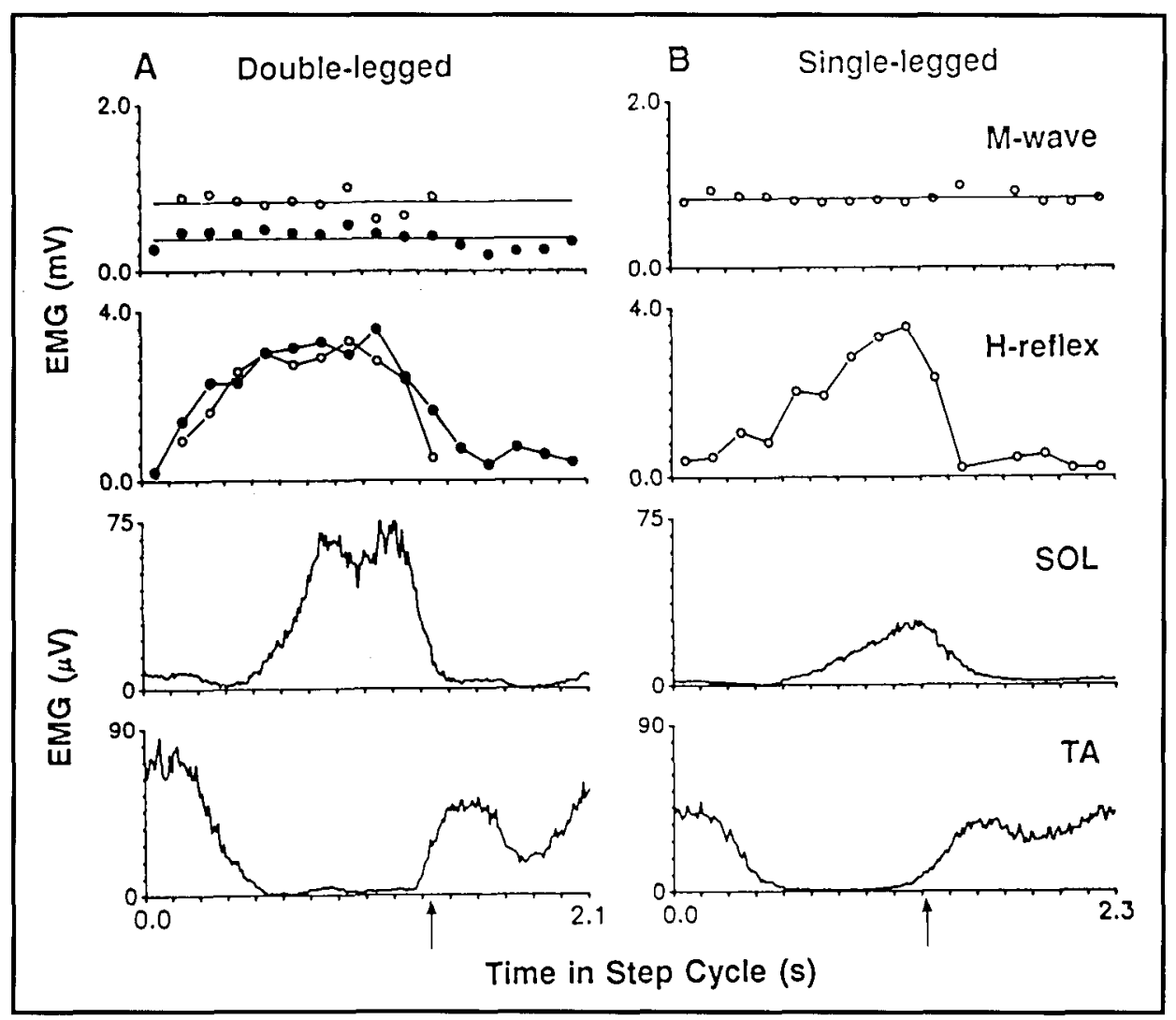

Figure $I-A$ ) The SOL $H$-reflex (second trace) is deeply modulated during slow treadmill walking $(0.6 \mathrm{~m} / \mathrm{s})$ in a normal subject, in spite of a relatively constant stimulus intensity, as reflected by the constant $M$-wave amplitude (first trace). Small changes in the stimulus intensity (open versus solid circles) did not affect the H-reflex amplitude. The SOL and TA activation during walking (bottom two traces, averaged over 50 strides) is shown from the time of heel-contact to the following heel-contact. B) Single-legged walking at the same speed required less activation of the SOL (third trace) and TA (fourth trace) muscles as compared to normal walking (compare A and B). Nevertheless, the pattern of modulation of the H-reflex was qualitatively similar to that obtained during normal walking. The arrows indicate the average time of transition from stance to swing. 
mal subjects, additional experiments were performed on 3 normal individuals. $\mathrm{H}$-reflexes were recorded while the subjects walked at a speed $(0.6 \mathrm{~m} / \mathrm{s})$ and in a manner (single and double legged) comparable to that of the patients. Second, the constancy of the M-wave amplitude, while a reasonable control for the effective stimulus strength within a subject, cannot be used for comparisons between subjects. Thus, the effect of stimulus intensity was estimated by eliciting $\mathrm{H}$-reflexes during walking at two different stimulus intensities (i.e., 2 levels of $\mathbf{M}$-wave amplitude) in 3 normal subjects and 3 patients who had good ambulatory endurance. Finally, many patients were on medication to reduce spasticity. The effect that these medications might have on the H-reflex during walking has yet to be investigated. Despite these confounding factors and the slight differences in experimental procedures followed at the 2 centres, the results obtained were remarkably similar between the centres. The same trends were observed in all the data.

\section{Results}

The EMG patterns of the SOL and TA muscles are shown for a normal subject walking at a slow speed $(0.6 \mathrm{~m} / \mathrm{s})$ in Figure $1 \mathrm{~A}$. Generally, the amplitude of the EMG is slightly lower than that observed at faster walking speeds, while the timing of these measures remained similar, as previously reported. ${ }^{20}$ The SOL EMG builds in a ramp-like fashion during the stance phase while the muscle is lengthening, and reaches a peak at push-off. The TA is active in a reciprocal manner, with a lengthening contraction near heel-contact (to control the lowering of the foot smoothly to the ground), and a shortening contraction during swing. Single-legged walking at the same speed is associated with a similar pattern of muscle activation but the amplitudes are much lower (Figure 1B).

In normal subjects, the SOL H-reflex is modulated at slow walking speeds much as it is for faster speeds. The reflex ampli-

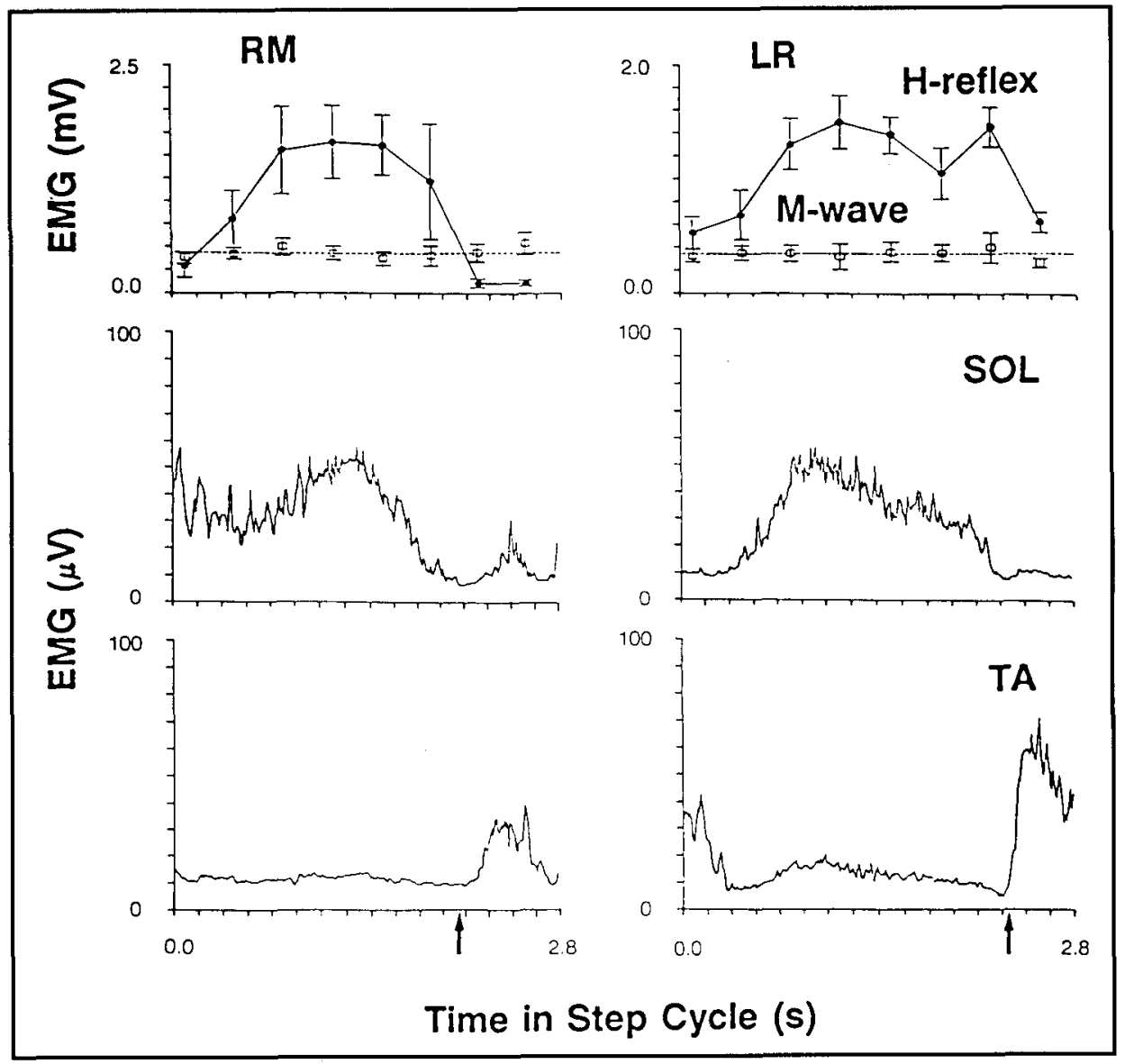

Figure $2-H$-reflex modulation in two mildly spastic patients (RM and $L R$ ) during double-legged walking. The H-reflex (filled circles, mean $\pm 1 S D$ ) was depressed during early stance, rose in a ramplike fashion during the stance phase, and was depressed during the swing phase, similar to that observed in healthy subjects. Slight abnormalities such as a prolonged elevation of the H-reflex amplitude at the stance-swing transition was noted in $L R$. The M-wave amplitude (open squares, mean \pm 1 $S D)$ remained relatively low and constant. The average amplitude of the $M$-wave over the walking cycle is indicated by the dashed line. The SOL and TA activation patterns during walking (middle and bottom traces, average of 10 strides) were reciprocal. Some abnormalities such as the oscillatory bursting pattern in the SOL and the absence of a TA burst at foot-floor contact were noted in RM. The arrows indicate the average time at which the swing phase began. 
tude rises more or less in parallel with the background SOL EMG in the step cycle, in spite of a constant effective stimulus, as reflected by the constant $\mathrm{M}$-wave amplitude (Figure $1 \mathrm{~A}$ ). The modulation pattern is independent of small changes in the stimulus intensity, since two different stimulus intensities resulted in a similar modulation pattern (Figure 1A). No differences were observed in the way the H-reflex was modulated during single versus double-legged walking (Figure 1B), in agreement with previous reports. ${ }^{4}$

Most patients showed some modulation of the H-reflex over the step cycle, but the degree of modulation was less than that seen in normal subjects. Examples are shown in Figures 2, 4 and 5, together with the EMG patterns of the SOL and TA muscles during walking. Figure 2 illustrates examples from two mildly spastic patients who could walk comfortably at a treadmill speed of $0.26 \mathrm{~m} / \mathrm{s}$ (subject RM) and $0.15 \mathrm{~m} / \mathrm{s}$ (subject LR). These two patients showed a gait pattern which in many respects is similar to the normal except for the prolonged stance and cycle duration. The reciprocal pattern of the SOL and TA was largely retained, although large repetitive bursts of the SOL during early stance was commonly observed (e.g., Figure 2, $\mathrm{RM}$, as previously reported ${ }^{21}$ ). This stretch related bursting pattern could be enhanced by increasing the walking speed (Figure 3 , subject $\mathrm{CH} 2$ ), suggesting that the response was velocity sensitive, and most likely associated with the la afferents. The early TA burst at foot-floor contact was reduced or absent in many patients, as ground contact was made with either the forefoot or with the foot flat (e.g., Figure 2, RM). The SOL H-reflex was low in early stance and increased progressively to peak during the push-off phase. The reflex was low during the swing phase, similar to that observed in normal subjects. Five patients showed this type of response. Evidence of a prolonged elevation of the reflex near the beginning of the swing phase was sometimes observed (e.g., Figure 2, LR).

Figure 4 illustrates examples from two moderately spastic patients who could walk comfortably at a treadmill speed of $0.32 \mathrm{~m} / \mathrm{s}$ (subject MB) and $0.5 \mathrm{~m} / \mathrm{s}$ (subject BP1). These patients showed a generally elevated $\mathrm{H}$-reflex response throughout the stance phase, with a slight inhibition during the swing phase. However, their SOL and TA muscle activation profiles remained largely reciprocal. Stretch-induced responses are clearly visible in the SOL during stance. Ten patients showed this type of reflex modulation pattern.

Six out of the 21 patients showed little or no H-reflex modulation throughout the walking cycle, as shown in Figure 5. These severely spastic patients showed elevated H-reflex amplitudes even at a very low stimulus intensity (note the low Mwave amplitudes in Figure 5). Functionally non-ambulatory, these two patients could only walk at a treadmill speed of 0.1 to $0.2 \mathrm{~m} / \mathrm{s}$. Sharp oscillating bursts of the SOL muscle were seen throughout the stance phase when the muscle was being stretched. The frequency of bursting was between 6 and $11 \mathrm{~Hz}$ for different patients, in the same frequency range associated with clonus. ${ }^{22}$ Sustained clonus was often elicited in these patients. The TA activity was very low in some patients during both the stance and swing phases (Figure 5, SH), and a corresponding reduction in dorsiflexion during the swing phase was often observed, resulting in toe drag.

The effect of stimulus intensity was examined in 3 patients. In one patient (Figure 6, $\mathrm{CH} 2$ ), a weak modulation pattern was elicited by a stimulus intensity which generates a clear modulation in normal subjects (i.e., M-wave approximately $1.0 \mathrm{mV}$ peak-to-peak). However, when weaker stimuli were applied (i.e., just visible $\mathrm{M}$-wave of approximately $0.3 \mathrm{mV}$ ), a deeper, more normal appearing modulation pattern emerged. This suggests that the reflex arc was saturated at the higher stimulus intensity. The normal modulation of the reflex during walking appears present in this subject, but can only be observed at low stimulus intensities. The same effect was observed in two out of the three subjects who could walk far enough to be tested at more than one $\mathrm{M}$-wave level.

The third patient showed no modulation of the H-reflex through the step cycle even when the stimulus intensity was lowered to just detectable levels of the M-wave (Figure 6, GB1). Either the mechanisms for generating cyclical modulation was absent in this patient, and/or the tonic reflex gain was exceptionally high (i.e., the reflex arc was saturated even at the lower stimulus intensity). Both the SOL and TA showed exaggerated stretch responses during walking in the subjects of Figure 6.

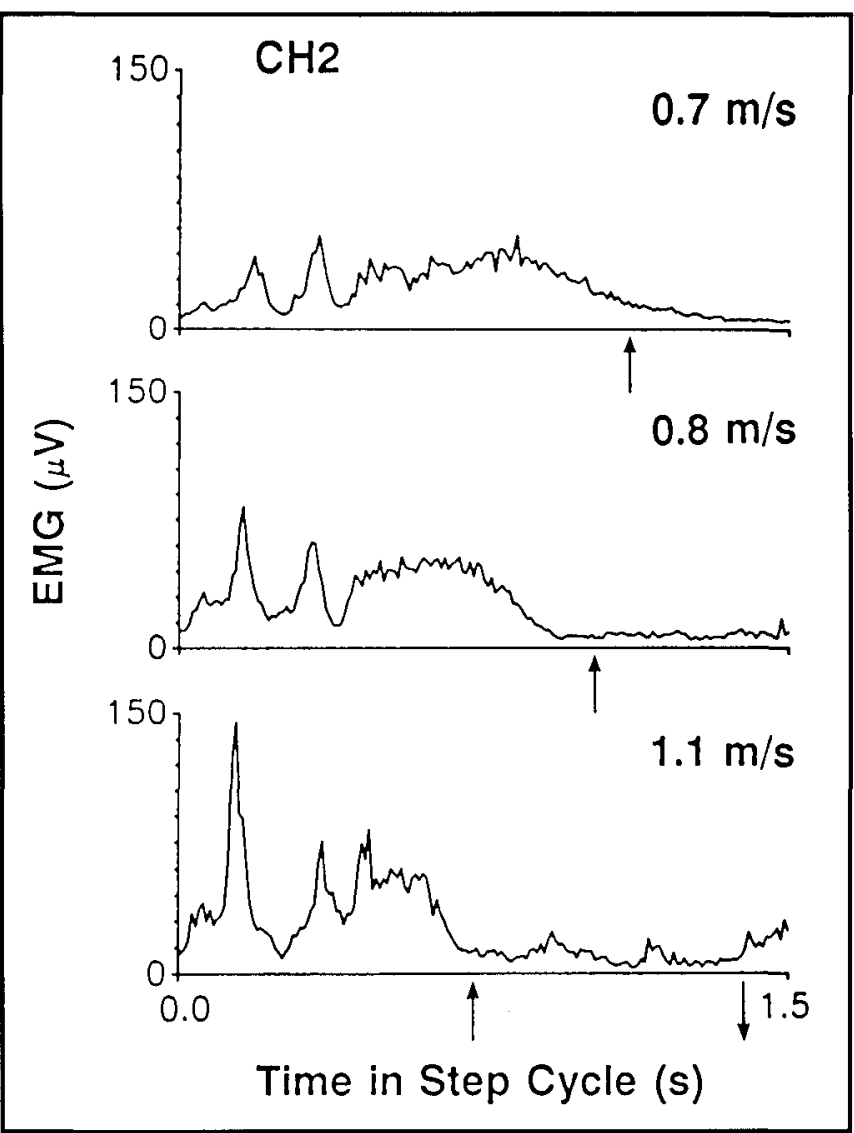

Figure 3 - The stretch induced bursting pattern of the SOL muscle during early stance phase is velocity sensitive. The amplitude of the EMG bursts increased with increasing walking speeds of $0.7,0.8$ and $1.1 \mathrm{~m} / \mathrm{s}$ in a patient $(\mathrm{CH} 2)$. Note that the time scale is identical for the three traces to allow a comparison of the timing of the stretch response. Because of the differences in cycle duration at each of the walking speeds, the top two traces do not represent the whole cycle, whereas the bottom trace represents slightly more than one cycle. Arrows pointing upward represent the time the foot is lifted off the ground at the stance-swing transition, and the arrow pointing downward in the bottom trace represents foot-floor contact of the next step. 

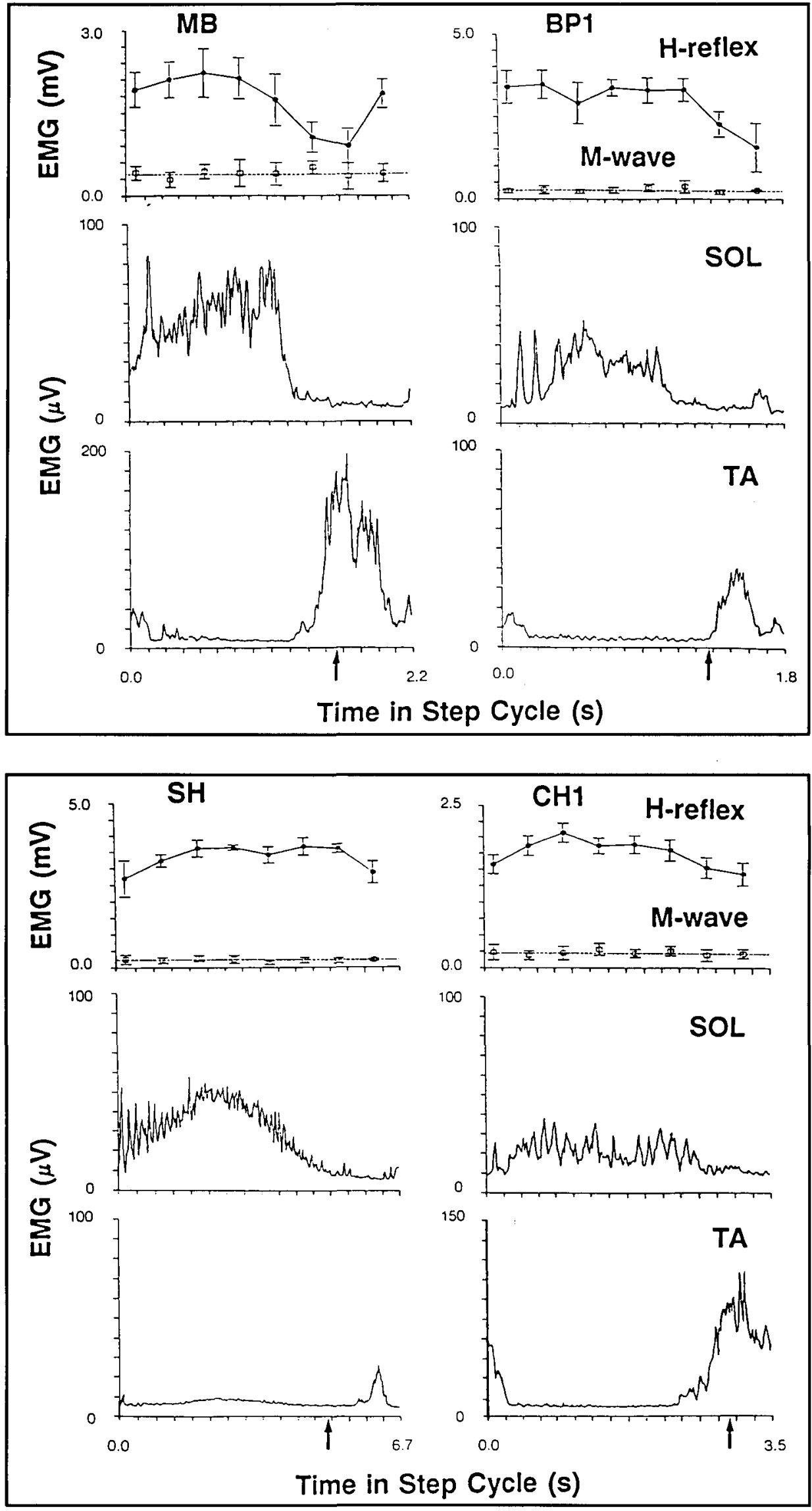

Figure 4-Examples from two moderately spastic patients (MB and BP1) show the most common reflex modulation pattern observed. The convention is identical to that in Figure 2. The H-reflex was high throughout the stance phase, and was depressed somewhat during the swing phase. Again, the SOL and TA profiles during walking were reciprocal, with some stretch induced responses in the SOL during early stance. The initial burst of the TA at the time of foot-floor contact was also reduced.
Figure 5-Examples from two severely spastic patients ( $\mathrm{SH}$ and $\mathrm{CHI}$ ) show almost no modulation of the SOL $\mathrm{H}$ reflex throughout the walking cycle. These patients show strong oscillatory bursts in the SOL during the stance phase when the muscle is lengthening, and some (such as patient SH) show minimal TA activity. 
Despite showing the lowest degree of reflex modulation measured, patient GB1 is a functional walker.

The degree of $\mathrm{H}$-reflex modulation was quantified by a modulation index:

$$
M I=(\max H-\min H) \times 100 / \max H
$$

where $\max \mathrm{H}$ and $\min \mathrm{H}$ refer to the maximum and minimum H-reflex amplitudes obtained during walking. The modulation index from a group of 22 normal subjects was $90 \% \pm 10 \%$. The mildly affected patients in Figures 2 and 3 showed modulation indexes greater than $65 \%$. The severely affected patients in Figure 5 showed modulation indexes of less than $30 \%$, while the moderately affected patients in Figure 4 had intermediate values. A modulation index can also be calculated for the stance phase alone. The modulation index for the stance phase was $75 \% \pm 14 \%$ for the normal subjects.

In our population of patients studied, spasticity developed from a variety of causes: spinal cord injury, head injury, or spastic paresis of non-familial origin (see Table 1). The modulation index from each of these groups were first considered separately, to determine if there were differences between the groups. The average modulation index for the walking cycle was $68 \%$, $76 \%$ and $49 \%$ for the spinal cord injured, head injured and spastic paretic patients, respectively, while the corresponding index for the stance phase was $36 \%, 39 \%$ and $16 \%$. Only one out of the six comparisons was significant ( $t$-test, $\mathrm{p}<0.05$ ). The modu- lation index during the stance phase was significantly higher in the spinal cord injured subjects than the patients with spastic paresis of non-familial origin. This difference was borderline, just reaching statistical significance at the 0.05 level. The number of subjects in two of the patient groups (head injured and spastic paretic) were very low, so a definitive statement regarding differences between the groups cannot be made. Nevertheless, these preliminary results suggest that there were no systematic differences as a function of the diagnosis. Therefore, the data from all patients were pooled.

Most patients showed a degree of modulation greater than $50 \%$ (Figure 7, open bars), with the depression of the reflex usually occurring in the swing phase. In contrast to normal subjects who show very low reflex amplitudes at the beginning of the stance phase, most patients showed very high reflex amplitudes throughout stance. The normal ramp-like pattern of reflex modulation was absent. This is reflected by the $\mathrm{H}$-reflex modulation index of the stance phase, in which the $\max \mathrm{H}$ and $\min \mathrm{H}$ are taken from the stance phase only. Only 5 patients showed a modulation index during stance of greater than $50 \%$ (hatched bars in Figure 7).

\section{Discussion}

The results presented here indicate that the $\mathrm{H}$-reflex is modulated to a lesser degree during walking in the patient group than

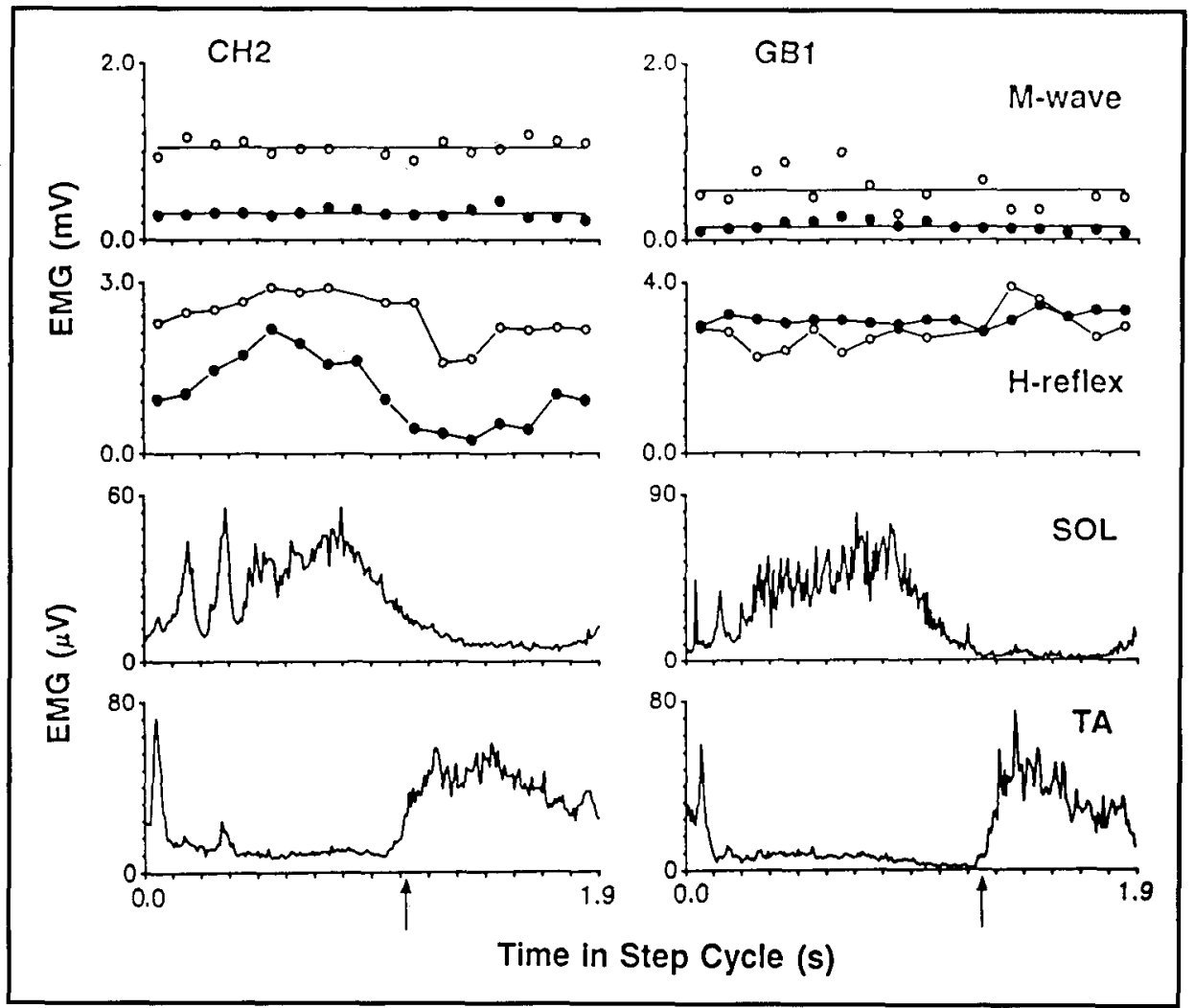

Figure $6-$ Two types of responses to a change in stimulus intensity were observed. Patient $\mathrm{CH} 2$ showed a small degree of modulation of the $H$-reflex when tested at a stimulus intensity which generated an $M$-wave amplitude of approximately $1 \mathrm{mV}$ p-p (open circles). At a lower stimulus intensity, however, a greater degree of reflex modulation was observed (filled circles). In contrast, patient GB1 showed no modulation of the reflex at either stimulus intensities. The SOL and TA activation patterns during walking contained abnormal stretch induced bursts of activity in both muscles. 
normal individuals. In some patients, the mechanisms which generate reflex modulation during walking appear to remain, but are largely masked by saturation of the reflex loop. In other patients, phasic modulation of the $\mathrm{H}$-reflex could not be demonstrated.

\section{Technical Considerations}

The experimental protocol required that the subjects be able to walk continuously for a few minutes. Since the patients differed in their ability to walk, different "types" of walking (i.e., single-legged versus double-legged) had to be used to suit their ability. The use of a single leg or both legs in treadmill walking was not associated with different patterns of H-reflex modulation in normal subjects (Figure 1).

The patients studied here represent a fairly diverse group of spastic paretic individuals. While the mechanisms responsible for their hyperactive reflexes may be different, the effect observed in walking was similar. Since the behaviour of the $\mathrm{H}$ reflex did not vary systematically either with the site of injury or with the type of walking, the results will be considered together.

Although the patients varied considerably in their ambulatory ability, most patients exhibited some reciprocal activation of the SOL and TA in walking. This reciprocal pattern is not always seen in individuals who have sustained more extensive damage to the CNS.21,23,24

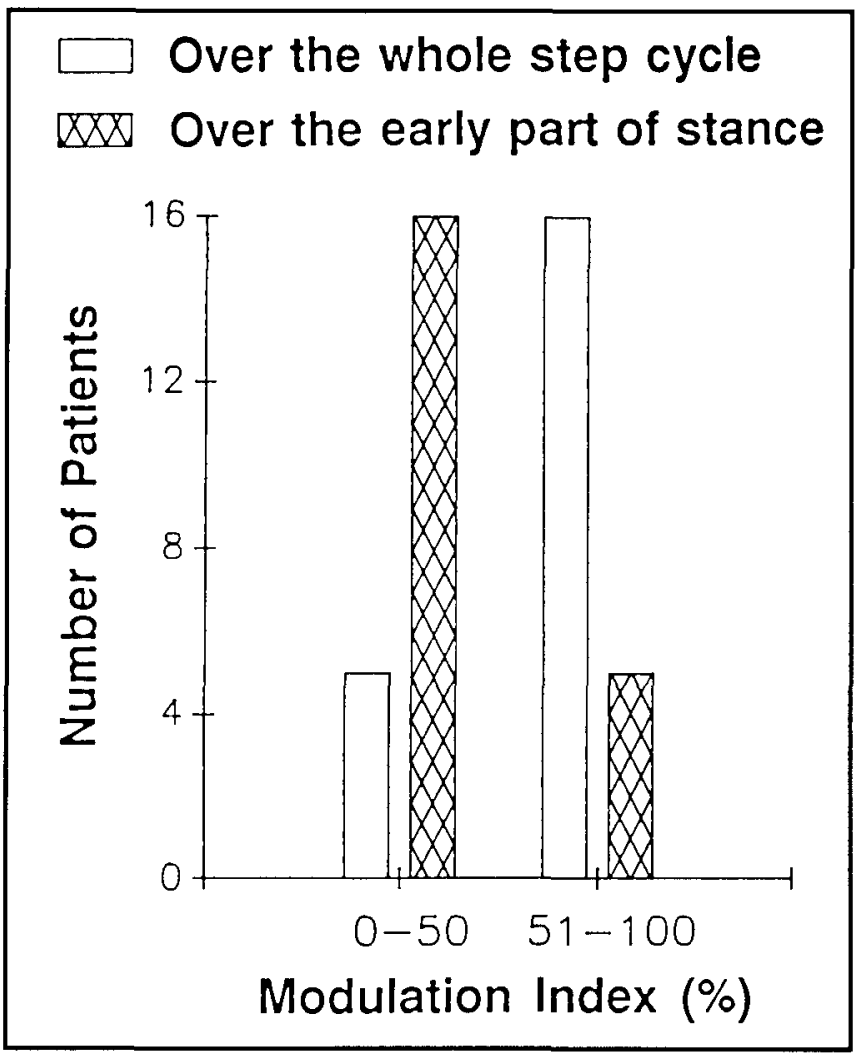

Figure 7-Most patients showed some modulation of the $\mathrm{H}$-reflex during walking. Sixteen patients showed a modulation index of greater than 50\% over the step cycle (open bars). That the reflex was depressed mainly during the swing phase is reflected by the opposite trend in the modulation index of stance (hatched bars). Only five patients showed a modulation index of more than $50 \%$ in the early stance phase.
What are the abnormal features of the H-reflex during walking?

At rest, most spinal cord injured patients exhibit hyperactive tendon ${ }^{8-10}$ and H-reflexes ${ }^{10,11}$ below the level of the injury. Similar responses have been reported after cerebral insult. 25 These abnormally high reflexes remain relatively unaltered during walking, as shown by the current results. The mechanisms underlying the hyperactive reflexes are unknown, although a number of possibilities have been suggested. Among the more likely are: 1) a reduction in presynaptic inhibition of primary afferent fibres,26,27 2) denervation supersensitivity 15 and 3) altered reciprocal inhibition. ${ }^{28}$ These mechanisms could exist in combination.

The possibility that presynaptic inhibition is reduced is particularly interesting here because the task-specific amplitude of the H-reflex appears to be controlled by presynaptic inhibition. ${ }^{5}$ In normal subjects the large reflex amplitude of standing is rapidly switched to a lower amplitude at the initiation phase of walking. ${ }^{29}$ These patients appear to retain a higher reflex gain during walking, as would be expected if presynaptic inhibition is impaired or reduced. However, the phasic modulation associated with walking could be observed in many patients by lowering the stimulus intensity. Hence, the mechanisms responsible for generating phasic modulation remain at least partially intact in these patients.

The mechanisms responsible for generating phasic modulation of the H-reflex in cyclical movements are unclear. The simplest explanation is that the H-reflex amplitude is a passive consequence of the excitability of the SOL motoneuron pool. Mechanisms such as phasic presynaptic inhibition could also modulate the reflex. ${ }^{30}$ It is likely that both central and peripheral mechanisms contribute to the cyclical modulation of the soleus H-reflex.

Peripheral factors associated with an altered gait could have contributed to the abnormal modulation of the reflex seen in these patients. For example, 9 out of 21 patients did not exhibit a proper heel-contact in walking, but rather made ground contact with the forefoot first (see Table 1). This places the soleus muscle at a shorter length than normal when the foot contacts the floor, a factor that could have contributed to the higher $\mathrm{H}$ reflex observed at this time in the step cycle. In some patients, the normal activity in the tibialis anterior at the time of footfloor contact was also absent. If reciprocal effects from the tibialis anterior are important in inhibiting the soleus H-reflex, this could have further contributed to the lack of modulation of the soleus $\mathrm{H}$-reflex. The importance of these factors will require further investigation. The current data suggest that there is no systematic relationship between the modulation index and either the foot-floor contact method (see Table 1) or the presence of tibialis anterior activity (compare subject RM in Figure 2 with subject GB1 in Figure 6). Preliminary results from normal subjects (Yang, unpublished observations) further suggest that factors such as muscle length and activation of the antagonist play a very minor role in inhibiting the soleus H-reflex during walking. It is likely that other factors were more important in producing the abnormalities observed in the H-reflex.

Since premammillary cats ${ }^{1}$ and spinal cats (Pearson, unpublished observations) exhibit H-reflex modulation during walking, the structures responsible for this modulation are presumably located in the spinal cord, although they have not been 
localized more precisely. The fibres exerting descending control from the supraspinal centres are partially interrupted in the patients studied here. Since phasic modulation of the reflex remained in most patients, this suggests either that the descending fibres which remained were able to generate the reflex modulation or that the modulation was generated by processes within the spinal cord, as in cats. Six patients, however, failed to exhibit any modulation through the step cycle, even at low stimulus intensities. It is unclear whether: 1) the mechanisms for rhythmic modulation of reflexes remained intact but were obscured because the reflex loop was saturated by the stimulus input, or 2) the mechanisms for generating the modulation were indeed impaired.

\section{How does the abnormal reflex amplitude affect functional walking?}

If the deep modulation of the SOL H-reflex in walking is functionally important, as previously suggested, ${ }^{3}$ then a reduction in the modulation observed in these patients should interfere with their forward progression. The current results suggest that this is indeed the case. Abnormally strong reactions to muscle stretch were seen during times in the step cycle when the $\mathrm{H}$ reflexes were abnormally high. Moreover, these stretch-induced responses were velocity sensitive which suggests that they may arise from activation of the la fibres 31 that are thought to be responsible for generating the $\mathrm{H}$-reflex. ${ }^{32}$ Finally, the muscle stretch often induced repetitive firing of the SOL muscle at a rate typical of clonus, which again is a response associated with Ia afferents. ${ }^{22}$

Two time periods in the walking cycle can be disrupted by exaggerated stretch responses in the SOL muscle: early stance and early swing. In the early part of the stance phase, the SOL H-reflex is low in normal individuals, which prevents exaggerated responses in the triceps surae as it is stretched by the rotation of the body over the foot. Exaggerated reflexes at this time in many patients resulted in large stretch-induced responses which interfered with the smooth forward progression of the body over the foot. In normal subjects, the swing phase is associated with very low H-reflex amplitudes in the SOL, which allows the ankle to dorsiflex without being impeded by stretchinduced responses from the triceps surae. In contrast, patients with abnormally active reflexes during the swing phase often had difficulty clearing the foot over the ground. However, this could be due more to low TA activity than the high level of $\mathrm{H}$ reflexes, since bursts of SOL activity were rarely seen at this time. Presumably, the SOL motoneurons are sufficiently hyperpolarized that asynchronous Ia activity does not cause them to fire, although the synchronous volley associated with the $\mathrm{H}$ reflex can still produce a large response.

\section{How might these reflex abnormalities be corrected?}

These results suggest that reflex modulation contributes to the attainment of normal walking, at least in the SOL muscle studied here. Efforts to improve the walking pattern of these patients should include methods to lower the reflex amplitude so that a normal pattern of reflex modulation can emerge.

In some patients, the main problem is a high tonic level of reflexes rather than the absence of phasic modulation in walking. Interventions which could lower the reflex amplitude might be useful. In this regard, pharmacological agents are an obvious choice. Baclofen has been administered systemically for some time to reduce spasticity, ${ }^{33}$ and was more recently introduced intrathecally. ${ }^{34}$ Cyproheptadine is effective in reducing stretchinduced responses and restoring walking in some spinal cord injured patients. ${ }^{15,16}$ Similarly, clonidine was recently reported to improve the vibration induced $\mathrm{H}$-reflex depression ${ }^{35}$ and improve the locomotor pattern. ${ }^{36}$ More recently, it has been shown that the combination of these medications and a training program with progressive weight support can restore locomotor function in chronic spinal cord injured subjects who were previously wheelchair-bound. ${ }^{37}$ It would be interesting to study the effect of these drugs on the pattern of reflex modulation in walking.

Many of the patients studied here were already on medication to reduce spasticity, yet their reflexes remained abnormally high and exaggerated stretch responses could not be eliminated during walking. Additional methods may be necessary to lower the reflex at appropriate phases in the step cycle. Methods that could control the reflex amplitude within 100 to $200 \mathrm{~ms}$ would be particularly desirable. This would allow more flexibility, not only to tailor the reflex amplitude for the particular task at hand, but also to modify the reflexes at different times in a movement, in such a way that mimics the control of the normal central nervous system. Preliminary results have shown that, in the moderately and severely impaired spastic paretic subjects, conditioning cutaneous stimulation delivered to the medial plantar region can selectively inhibit the soleus $\mathrm{H}$-reflex in both the early stance and swing phases during walking. ${ }^{38}$

\section{ACKNOWLEDGEMENTS}

The project was supported by grants from the Medical Research Council to Drs. R.B. Stein and H. Barbeau, and a grant from the Rick Hansen Man in Motion Legacy Fund for spinal cord research to Dr. H. Barbeau. Drs. J.F. Yang and M. Edamura were post-doctoral fellows of the Alberta Heritage Foundation for Medical Research and the Rick Hansen Man in Motion Legacy Fund respectively. Ms. J. Fung and Mr. R. Blunt were supported by scholarships from the Rick Hansen Man in Motion Legacy Fund and the Medical Research Council of Canada respectively. Dr. H. Barbeau is a Chercheur-Boursier of the Fonds de la Recherche en Santé du Québec. The authors thank Dr. J. Nagy for selecting the head injured patients for participation in the study and for assisting in some of the experiments.

\section{REFERENCES}

1. Akazawa K, Aldridge JW, Steeves JD, et al. Modulation of stretch reflexes during locomotion in the mesencephalic cat. J Physiol (Lond) 1982; 329: 553-567.

2. Forssberg H, Grillner S, Rossignol S. Phasic gain control of reflexes from the dorsum of the paw during spinal locomotion. Brain Res 1977; 132: 121-139.

3. Capaday C, Stein RB. Amplitude modulation of the soleus H-reflex in the human during walking and standing. J Neurosci 1986; 6 : 1308-1313.

4. Crenna P, Frigo C. Excitability of the soleus H-reflex arc during walking and stepping in man. Exp Brain Res 1987; 66: 49-60.

5. Capaday C, Stein RB. Difference in the amplitude of the human soleus $\mathrm{H}$-reflex during walking and running. J Physiol (Lond) 1987; 392: 513-522.

6. Forssberg H. Stumbling corrective reaction: a phase dependent compensatory reaction during locomotion. J Neurophysiol 1979; 42: 936-953.

7. Ashby P, McCrea D. Neurophysiology of spinal spasticity. In: Davidoff RA, ed. Handbook of the Spinal Cord. New York: Marcel Dekker 1987: 119-143. 
8. Dietrichson $P$. The role of the fusimotor system in spasticity and Parkinsonian rigidity. In: Desmedt JE, ed. New Developments in Electromyography and Clinical Neurophysiology. Basel: Karger 1973; 3: 496-507.

9. Ashby P, Verrier M, Lightfoot E. Segmental reflex pathways in spinal shock and spinal spasticity in man. J Neurol Neurosurg Psychiatry 1974; 37: 1352-1360.

10. Taylor S, Ashby P, Verrier $M$. Neurophysiological changes following traumatic spinal lesions in man. J Neurol Neurosurg Psychiatry 1984; 47: 1102-1108.

11. Little JW, Halar EM. H-reflex changes following spinal cord injury. Arch Phys Med Rehabil 1985; 66: 19-22.

12. McLellan DL. Co-contraction and stretch reflexes in spasticity during treatment with baclofen. J Neurol Neurosurg Psychiatry 1977; 40: 30-38.

13. Corcos DM, Gottlieb GL, Penn RD, et al. Movement deficits caused by hyperexcitable stretch reflexes in spastic humans. Brain 1986; 109: 1043-1058.

14. Young RR, Delwaide PJ. Drug therapy: spasticity. New Engl J Med 1981; 304: 28-33, 96-99.

15. Wainberg M, Barbeau H, Gauthier S. Quantitative assessment of the effect of cyproheptadine on spastic paretic gait: a preliminary study. J Neurol 1986; 233: 311-314.

16. Wainberg M, Barbeau $H$, Gauthier $S$. The effects of cyproheptadine on locomotion and on spasticity in spinal cord injured patients. $J$ Neurol Neurosurg Psychiatry 1990; 53: 754-763.

17. Yang JF, Stein RB, Edamura M. Monosynaptic reflexes during walking in patients with spasticity. Can J Physiol Pharmacol 1989; 67: A41.

18. Fung J, Blunt R, Barbeau $H$. The soleus H-reflex modulation pattern in spastic paretic subjects during standing and walking. In: Brandt Th, Pauluo W, Bleo W, Dieterich M, Krafczyk S, Straube A, eds. Disorders of Posture and Gait. New York: Thieme 1990; 398-401.

19. Hugon M. Methodology of the Hoffmann reflex in man. In: Desmedt JE, ed. New Developments in Electromyography and Clinical Neurophysiology, Basel: Karger 1973, 3: 277-293.

20. Yang JF, Winter DA. Surface EMG profiles during different walking cadences in humans. Electroencephalogr Clin Neurophysiol 1985; 60 : 485-491.

21. Fung J, Barbeau H. A dynamic EMG profile index to quantify muscular activation disorder in spastic paretic gait. Electroencephalogr Clin Neurophysiol 1989; 73: 233-244.

22. Stein RB, Lee R. Tremor and Clonus. In: Brook V, ed. Handbook of Physiology, Sec I, Vol. II Part 1, Baltimore: Waverly Press, $1981 ; 325-344$.
23. Peat M, Dubo HIC, Winter DA, et al. Electromyographic temporal analysis of gait: hemiplegic locomotion. Arch Phys Med Rehabil 1976; 57: 421-425.

24. Knutsson E, Richards C. Different types of disturbed motor control in gait of hemiparetic patients. Brain 1979; 102: 405-430.

25. Somerville J, Ashby P. Hemiplegic spasticity: neurophysiologic studies. Arch Phys Med Rehabil 1978; 59: 592-596.

26. Burke D, Ashby P. Are spinal "presynaptic" inhibitory mechanisms suppressed in spasticity? J Neurol Sci 1972; 15: 321-326.

27. Ashby P, Stalberg E, Winkler T, et al. Further observations on the depression of group Ia facilitation of motoneurons by vibration in man. Exp Brain Res 1987; 69: 1-6.

28. Ashby P, Wiens M. Reciprocal inhibition following lesions of the spinal cord in man. J Physiol (Lond) 1989; 414: 145-157.

29. Edamura E, Yang JF, Stein RB. Factors that determine the magnitude and time course of human H-reflexes in locomotion. J Neurosci 1991; 11: 420-427.

30. Dubuc R, Cabelguen J-M, Rossignol S. Rhythmic fluctuations of dorsal root potentials and antidromic discharges of primary afferents during fictive locomotion in the cat. J Neurophysiol 1988; 60: 2014-2036.

31. Matthews PBC. Evolving views of the internal operation and functional role of the muscle spindle. J Physiol (Lond) 1981; 320: 130.

32. Magladery JW, McDougal DB Jr. Electrophysiological studies of nerve and reflex activity in normal man. I. Identification of certain reflexes in the electromyogram and the conduction velocity of peripheral nerve fibres. Bull Johns Hopkins Hosp 1950; 86: 265-290.

33. Davidoff RA. Antispasticity drugs: mechanisms of action. Ann Neurol 1985; 17: 107-116.

34. Penn RD, Kroin JS. Long-term intrathecal baclofen infusion for treatment of spasticity. J Neurosurg 1987; 66: 181-185.

35. Nance PW, Shears AH, Nance DM. Reflex changes induced by clonidine in spinal cord injured patients. Paraplegia 1989; 27: 296-301.

36. Stewart JE, Barbeau H, Gauthier S. Modulation of locomotor patterns and spasticity with clonidine in spinal cord injured patients. Can J Neurol Sci 1991, 18: 321-331.

37. Fung J, Stewart JE, Barbeau $H$. The combined effects of clonidine and cyproheptadine with interactive training on the modulation of locomotion in spinal cord injured subjects. J Neurol Sci 1990; 100: 85-93.

38. Fung $\mathbf{J}$, Barbeau $H$. The effects of conditioning musculo-cutaneous stimulation on the soleus H-reflex during walking in spastic paretic subjects. Soc Neurosci Abstr 1991; 16(2): 1262. 